DOI: http://dx.doi.org/10.22201/iie.18703062e.2005.87.2191

ROBERTO L. MAYER

\title{
Trasmonte y Boot
}

\section{Sus vistas de tres ciudades mexicanas en el siglo XVII}

\begin{abstract}
juzgo que quien posea un pequeño caudal de erudición debe ponerlo a la disposición de los demás, favoreciendo así los estudios ajenos como aliciente y para la investigación de la verdad que a todos nos interesa por igual. -Francisco del Paso y Troncoso ${ }^{\mathrm{I}}$
\end{abstract}

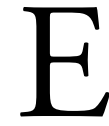

N la primera mitad del siglo Xvir, Juan Gómez de Trasmonte pintó una vista de México y Adrián Boot sendas vistas de Acapulco y Veracruz, hoy sólo conocidas por cromolitografías impresas a principios del siglo xx y frecuentemente reproducidas con fines decorativos. La colección iconográfica del Instituto de Investigaciones Estéticas, por fortuna, cuenta con estas vistas que, hasta hace algunas décadas, estaban a la venta en el Museo Nacional y hoy son muy codiciadas por los coleccionistas (figs. I, 2 y 3). El determinar dónde se encuentran, o encontraban, las pinturas originales ha sido tema de investigación y especulación a través de varias generaciones.

Las cromolitografías fueron estampadas en Florencia en $1907^{2}$ por encargo de don Francisco del Paso y Troncoso (Veracruz, I842-Florencia, I916), erudito e incansable investigador de historia y en una época director del Museo

I. Silvio Zavala, Francisco del Paso y Troncoso. Su misión en Europa (I892-I916), México, Publicaciones del Museo Nacional-Departamento Autónomo de Prensa y Publicidad, I938. Tomado del prólogo "El deporte americanista". Todos los textos antiguos se han transcrito con la ortografía y puntuación originales.

2. Talleres Gráficos de A. Ruffoni, Piazza S. Croce 20. 


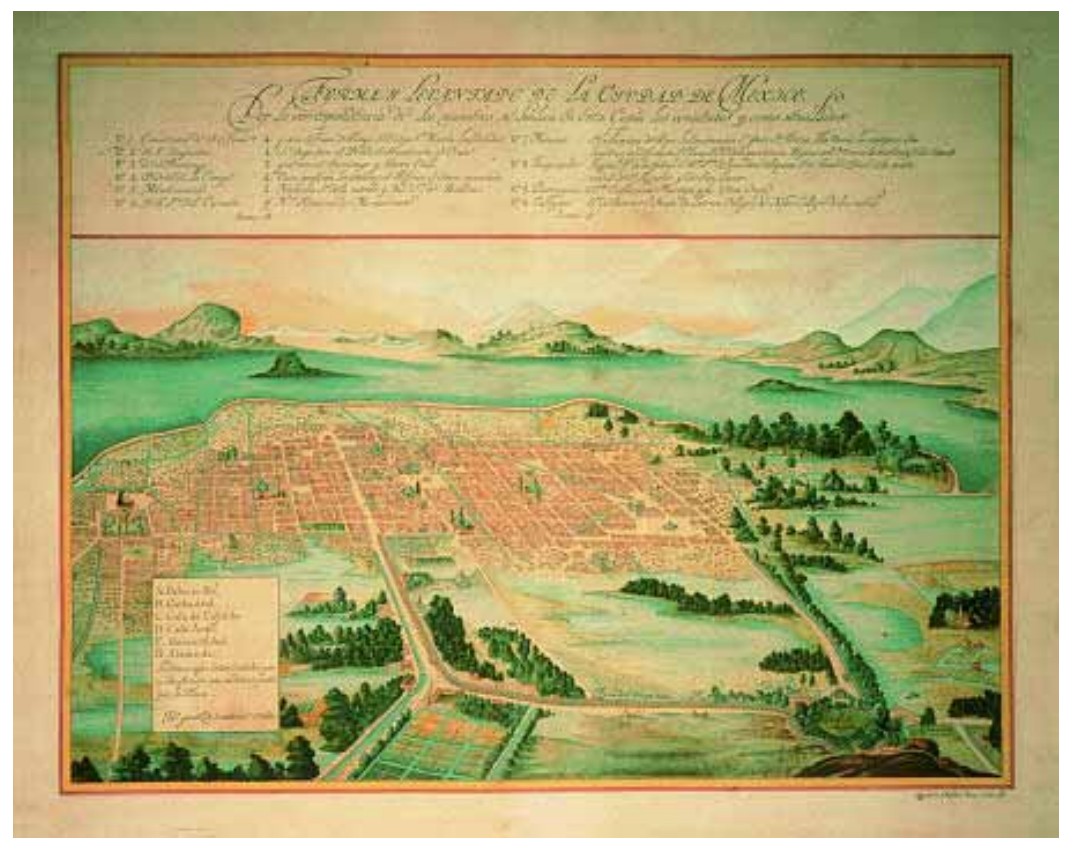

I. Forma y levantado de la ciudad de México, Taller de A. Ruffoni según dibujo de Johannes Vingboons basado en una pintura de Juan Gómez de Trasmonte, Florencia, 1907, cromolitografía, $42 \times 55 \mathrm{~cm}$. Colección: Instituto de Investigaciones Estéticas, UNAM.

Nacional de México. ${ }^{3}$ La vista de la ciudad de México fue analizada desde los puntos de vista histórico por Manuel Toussaint, urbanístico por Justino Fernández y bibliográfico por Federico Gómez de Orozco, tres distinguidos miembros del Instituto de Investigaciones Estéticas, en el libro Planos de la ciudad de México. ${ }^{4}$

3. Jesús Galindo y Villa, Don Francisco del Paso y Troncoso (agosto 30, I9I6), México, Anales del Museo Nacional de Arqueología, Historia y Etnografía, época 4a, t. I, 1922. En las páginas 305-33r aparece una extensa biografía de Troncoso. En la página 306 el autor aclara que el nombre completo era Francisco de Borja del Paso y Troncoso. "Sus familiares le llamaban cariñosamente Borja y sus amigos y conocidos por el segundo apellido de su señor padre, don Pedro del Paso y Troncoso, casado con doña Teodora Medina." Nació en Veracruz en octubre de 1842 y falleció en Florencia en abril de i9ı6.

4. Manuel Toussaint, Federico Gómez de Orozco y Justino Fernández, Planos de la ciudad 


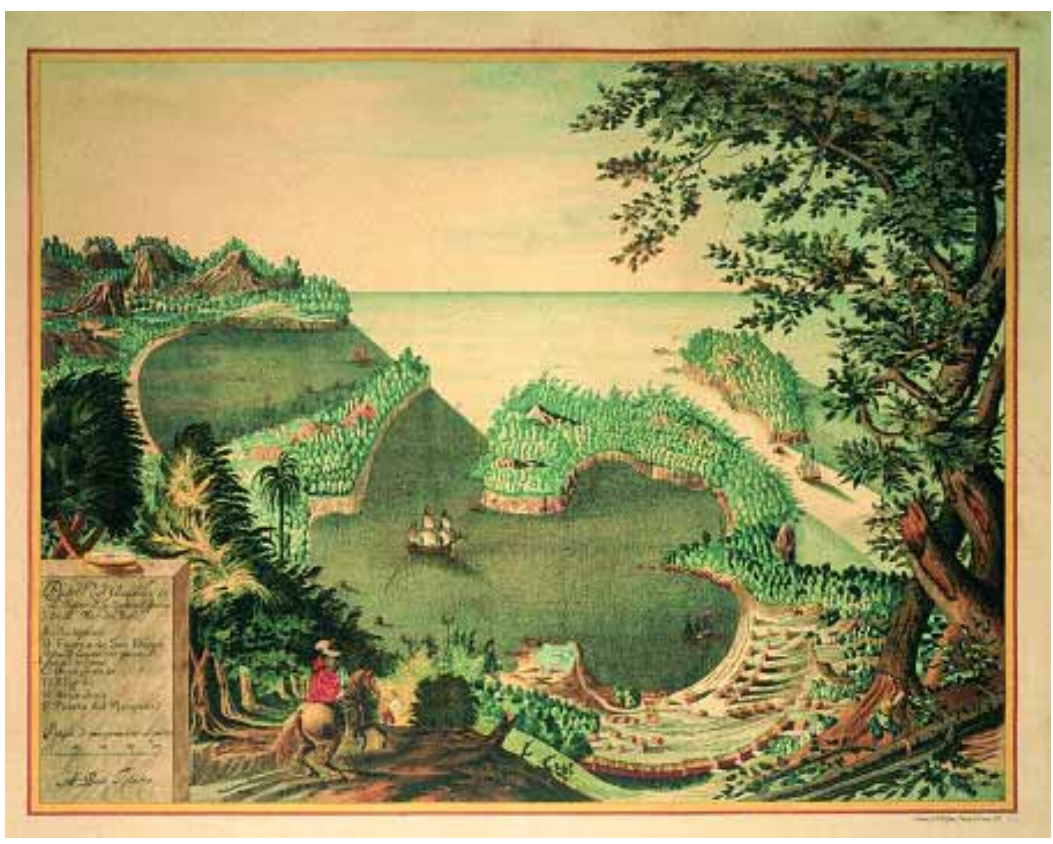

2. Puerto de Acapulco en el reino de la Nueva España en el mar del Sur, Taller de A. Ruffoni según dibujo de Johannes Vingboons, basado en una pintura de Adrián Boot, Florencia, 1907, cromolitografía, $43 \times 55 \mathrm{~cm}$. Colección: Instituto de Investigaciones Estéticas, UNAM.

Gómez de Orozco escribió en la susodicha obra:

Perdido para México, en una colección privada en Bélgica, fue encontrado este plano por el señor Francisco del Paso y Troncoso, director del Museo Nacional de México, en misión en Europa, y con él, tal vez en la misma colección otros dos planos de gran importancia histórica y evidente valor artístico, los de las ciudades y puertos respectivos de Veracruz y Acapulco, ejecutados ambos por el ingeniero belga [sic] Adrián Boot, director [sic] de las obras del desagüe del Valle de México, y contemporáneo de Gómez de Trasmonte.

de México. Contribución del Instituto de Investigaciones Estéticas, Universidad Nacional Autónoma de México, al XVI Congreso Internacional de Planificación y de la Habitación, México, 1938. 
Y continúa:

La discreción proverbial del señor Troncoso, sólo le permitió indicar en una carta privada, que el plano de México pertenecía a una colección particular, por lo que ha sido grande nuestra satisfacción al saber que un excelente y viejo amigo nuestro tiene actualmente, en su poder, en México, los originales del plano de nuestra ciudad y el del puerto de Acapulco, que de este modo volvieron al lugar de su origen. ${ }^{5}$

Seguramente por su propia discreción, Gómez de Orozco no nos dice a quién dirigió Troncoso esa carta privada y cómo se enteró de ella, ni el nombre de su amigo poseedor de los originales que menciona.

Aparentemente, Gómez de Orozco desconocía o no tuvo a su alcance la obra de Galindo y Villa que reúne los escritos de Troncoso y que se menciona más adelante, pues los datos que aporta no concuerdan con ellos. Lamentablemente, la información inexacta que se cita en el párrafo anterior ha sido repetida por varios autores al comentar las vistas que nos ocupan y otros les han atribuido diversas procedencias, también incorrectas. ${ }^{6}$

En la British Library y en la Royal Geographical Society de Londres este autor tuvo oportunidad de consultar sendos ejemplares de la obra Monumenta cartographica, ${ }^{7}$ notable por dos hechos: por sus enormes dimensiones que le permiten reproducir vistas y planos al tamaño original y, más importante, por tratarse de una cuidadosa recopilación comentada de los trabajos cartográficos más sobresalientes. En su cuarto volumen aparecen copias esquemáticas de unos dibujos acuarelados que forman parte de un atlas ma-

5. Ibidem, p. I9I.

6. Martha Fernández, Arquitectura y creación. Relación de los servicios de Juan Gómez de Trasmonte, México, Textos Dispersos (núm. 49), 1994. Esta autora señala que Mariano Cuevas, en Historia de la Iglesia en México, t. III, p. 40, afirma que el plano fue encontrado en Florencia y que Francisco de la Maza, en La ciudad de México en el siglo XVII, p. I83, dice estar de acuerdo. Fernández, en Arquitectura y gobierno virreinal, México, Universidad Nacional Autónoma de México-Instituto de Investigaciones Estéticas, 1985 , muestra el plano de Trasmonte en la lámina II, con este pie de ilustración: "del original existente en la Biblioteca Laurenciana Medicea (dato que agradezco al Dr. Elías Trabulse)”. Carrera Stampa (véase nota 26) sigue la versión de Gómez de Orozco.

7. Frederick Caspar Wieder, Monumenta cartographica. Reproductions of Unique and Rare Maps, Plans and Views in the Actual Size of the Originals; Accompanied by Cartographical Monographs, La Haya, Martinus Nijhoff, 1925-1933. 


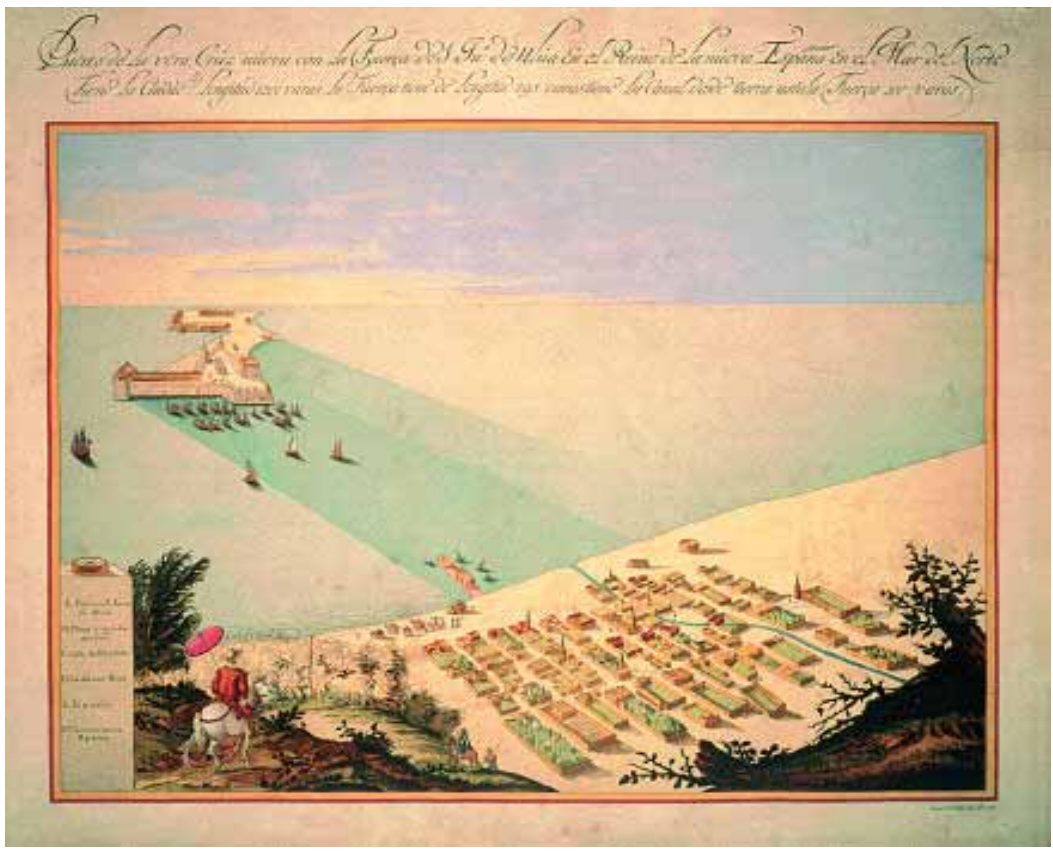

3. Puerto de la Vera Cruz, Taller de A. Ruffoni según dibujo de Johannes Vingboons basado en una pintura de Adrián Boot, Florencia, 1907. Colección: Instituto de Investigaciones Estéticas, unAM.

nuscrito, conservado en la Biblioteca Apostólica Vaticana, hechos por Johannes Vingboons en Amsterdam en i665. Las ilustraciones son cuatro: una vista y un plano de la ciudad de México, basados en pinturas de Juan Gómez de Trasmonte, y una vista de Acapulco y otra de Veracruz basadas en pinturas de Adrián Boot.

Se sabe poco de Vingboons; según una fuente, nació en Rotterdam; según otra, en Amsterdam en I6I7; se cree que falleció en esa misma ciudad en 1670. Aparentemente su familia era de origen flamenco y varios de sus miembros se dedicaban al dibujo, a la pintura y al grabado. Vingboons acompañó al pintor Post en un viaje a Brasil y, a su regreso, se dedicó al oficio de grabador, siendo su principal actividad el producir atlas con mapas y vistas manuscritos para la casa 
editora de cartografía más importante de aquella época, la de la dinastía Blaeu; al parecer también trabajó para las compañías holandesas de las Indias Orientales y Occidentales, las cuales guardaban sus atlas en el mayor secreto. ${ }^{8}$

El doctor Frederick Caspar Wieder (1874-I943), autor de Monumenta cartographica, quien demuestra en su escrito pletórico de información ser un investigador acucioso, conocedor y serio, menciona cuatro pinturas que a la sazón se encontraban en el Stedelijk Museum van Oudheden (Museo Municipal de Antigüedades) de Midelburgo, Holanda: una vista y un plano de la ciudad de México por Juan Gómez de Trasmonte, y una vista de Veracruz y otra de Acapulco por Adrián Boot. Wieder continúa diciendo que el archivista de Midelburgo, el doctor W. S. Unger, le proporcionó toda la información relativa a estas ilustraciones, a las que compara con las de Vingboons; dicha información, traducida al castellano, se publicó en mi obra, Poblaciones mexicanas, planos y panoramas. Siglos XVI a XIX. ${ }^{9}$

El doctor Wieder, teniendo a la mano los datos anteriores y los catálogos del museo de Midelburgo de I9Io y I93I, comenta que no hay duda de que estos cuadros sean los originales para las ilustraciones de Vingboons. Además, señala que probablemente son los mismos cuadros que ya se mencionan en los inventarios del palacio del ayuntamiento de la misma población en 1632, I707 y $1763 .{ }^{\text {Io }}$ Consideramos que la palabra "probablemente" obedece a un exceso de cautela por parte de Wieder, ya que sería mucha coincidencia que en la misma población de Holanda se encontraran dos grupos de cuatro cuadros que respondieran a la misma descripción.

Con el deseo de consultar al Stedelijk Museum van Oudheden, se solicitó su dirección a la embajada de los Países Bajos en México y orientación para contactarlo; la contestación, que tardó largo tiempo en llegar, fue que resultaba imposible encontrar ese museo, pero se proporcionaron los datos de otro localizado en la misma población. Consultado el nuevo museo, la respuesta fue muy escueta: informaba que el establecimiento que buscábamos en la po-

8. Cornelis Koeman, Atlantes neerlandici (Bibliography of Terrestrial, Maritime and Celestial Atlases and Pilot Books, Published in the Netherlands up to I880), 6 vols., Amsterdam, Theatrum Orbis Terrarum, 1967-1985. También E. Bénezit, Dictionnaire critique et documentaire des peintres, sculpteures, dessinateurs \& graveurs de tous les temps et de tous les pays, París, R. Roger \& F. Chernoviz, 1924, pp. I006-I007. Véase además el texto de Wawrik en la nota I3.

9. Roberto L. Mayer, Poblaciones mexicanas, planos y panoramas, siglos XVI a XIX, México, Smurfit Cartón y Papel de México, I998, pp. 95-II9.

Io. Wieder, op. cit., vol. 4, p. 98. 
blación costera de Midelburgo había sufrido un incendio y que las llamas destruyeron todo su contenido en 1940. Así que las pinturas originales de Juan Gómez de Trasmonte y Adrián Boot, de incalculable valor histórico y cartográfico para México, se sumaron a las muchas víctimas inocentes de la segunda guerra mundial al ser invadida Holanda por el ejército nazi.

Si las obras seminales ya no están a nuestro alcance, por lo menos se pueden localizar sus más cercanas copias. Además del atlas de Vingboons que se encuentra en la Biblioteca Apostólica Vaticana, Wieder menciona los de la colección Castello, el Atlas del príncipe Eugenio de Saboya y otros. ${ }^{\text {II }}$ El curador de mapas de la Royal Geographical Society aclara que la colección Castello se encuentra en la Biblioteca Medicea Laurenziana de Florencia, cuyo bibliotecario, Mario Tesi, escribió sobre la forma en que llegaron a su institución, ${ }^{12}$ y el Atlas del príncipe Eugenio de Saboya, en la Österreichische Natio-

II. Ibidem, p. I35. Según Wieder, hay hojas sueltas de uno o más atlas de Vingboons dispersas en París, Washington, Recife, Holanda y colecciones varias.

I2. Mario Tesi, Monumenti di cartografia a Firenze (s. X-XVII), Biblioteca Medicea Laurenziana. IX Conferenza Internazionale di Storia della Cartografia (Pisa-Florencia-Roma, mayo-junio de 198I) escribe:

“Las 82 'Carte di Castello' se llaman así porque hasta I92I se conservaron en la Villa Medicea di Castello cercana a Florencia. Fueron adquiridas en Amsterdam en 1667 por Cósimo III, durante el primero de sus dos viajes a través de varios países de Europa entre i667 y I669. En la relación del viaje hecha por Filippo Corsini, cuyo manuscrito se encuentra en el Archivo del Estado de Florencia (publicado en Amsterdam en I9I9 por G. J. Hoogenwerf), se dice que Cósimo III 'volvió a la sede de la Compañía de las Indias con más tiempo y espacio para considerar todo minuciosamente. Saliendo fue a la famosa estampería del señor Johannes Blaeu [...] donde se detuvo mucho tiempo [...] y por el 22 salió a ver una casa privada con diversas curiosidades de las Indias [...] El 24 retornó S. A. a casa y pasó la víspera con Blaeu viendo algunas cartas geográficas dibujadas e iluminadas con extraordinaria exquisitez [...] y mostraban planos de diversos puertos, fuertes y costas de las Indias, tanto Orientales como Occidentales'.

"Y con Johannes Blaeu, librero y burgomaestre de Amsterdam, que como guía estuvo siempre cercano a él durante el mes que permaneció en esa ciudad, el príncipe mediceo visitó, ya sea por curiosidad, ya sea para hacer adquisiciones o negocios, casas particulares y estudios de pintores. Su interés por las cartas geográficas y otros documentos aparece dos veces más en las Relaciones de Corsini: 'El lunes 26 [de diciembre de $1667 \ldots$... se dirigió a casa de Blaeu para ver algunas cartas geográficas [...]' y una semana después, el lunes 2 de enero de I668, 'fue con Blaeu a ver en casa del abogado Wandrem un despacho con un conjunto de dibujos de diversas ciudades, costas y lugares de las Indias, excelentemente iluminados, y otros mapas geográficos universales y regionales hechos a mano con toda clase de exquisitez imaginable'. Sin embargo, después de tres siglos su 'extraordinaria exquisitez' ya no es la misma. Acuarelados, expuestos por un periodo largo sin protección alguna contra la acción del polvo, la humedad 
nalbibliothek de Viena. Esta última biblioteca precisó que al atlas señalado se le conoce actualmente como el Atlas Blaeu-Van der Hem, y, a la pregunta de por qué el nombre de un atlas se cambió, respondió que fue un coleccionista de nombre Laurentius van der Hem (I62I-I680) quien lo formó tomando como base un atlas de Blaeu; su hija Agatha lo vendió en 1730 al príncipe Eugenio de Saboya por la entonces muy respetable suma de 122 ooo florines; la institución que actualmente lo conserva le ha dado el nombre de su editor junto con el de su propietario original, como un homenaje muy merecido al asiduo coleccionista que lo formó. Franz Wawrik, bibliotecario del repositorio, escribió extensamente sobre la historia de tan notable atlas. ${ }^{13}$

y otros agentes dañinos, presentan casi todos pérdidas más o menos graves de color, manchas, moho y señales de la desaparición de los números de inventario al óleo, puestos en diversas épocas sobre la tela a la que estaban pegados. La limpieza consecuente a la restauración les ha restituido su aspecto original, pero sólo parcialmente.

"Todo el conjunto de la colección presenta un panorama bastante completo de la actividad exploradora y de la navegación del siglo xviI, cuando la potencia comercial de Portugal era reemplazada, especialmente en Asia, por Holanda y cuando se iniciaba la potencia colonial inglesa" (traducción del autor).

13. Franz Wawrik, a continuación se reproducen fragmentos traducidos de Darstellung Amerikas im Atlas Blaeu-Van der Hem, en Österreich und die Neue Welt, Symposium in der Österreichischen Nationalbibliothek, Tagungsband, Viena, Elizabeth Zeilinger, 1993. (Wawrik es el director de la biblioteca.)

"El objeto más valioso que se conserva en la Biblioteca Nacional de Austria es, sin duda alguna, el Atlas Blaeu-Van der Hem. La obra goza de fama mundial y es tan conocida entre los círculos interesados en cartografía que aquí sólo se requiere una descripción breve.

"El Atlas Blaeu-Van der Hem es un atlas barroco compilado que consta de 50 tomos con más de 2 Ioo hermosos mapas, planos, vistas y escenas populares elaborados mediante gran diversidad de técnicas tales como grabado de cobre coloreado, acuarela, dibujo a lápiz, a pluma y sanguina. La concepción de esta obra singular y gigantesca se debe a Laurens van der Hem (I62I-1678), uno de los más extraordinarios coleccionistas de Holanda. El muy acaudalado abogado usó como punto de partida el Atlas mayor compuesto por ir volúmenes que en conjunto abarcan unas 600 cartas y aparecido en Amsterdam en I66I en la casa editorial de su amigo Joan Blaeu, uno de los más importantes productores de cartografía del siglo XVII. A esta base de cartas agregó Van der Hem innumerables hojas, incluso las de otros muchos autores.

"En el tomo 44 del Atlas Blaeu-Van der Hem queda representada cartográficamente América y lleva como portada la del tomo in del Atlas Mayor de Joan Blaeu, edición de 1662 en latín. Contiene 26 grabados en cobre coloreado y I3 dibujos [...]

"La mayor parte de las exquisitas cartas manuscritas se vincula con el artista Joannes Vingboons, oriundo de Amsterdam (I617-1670), quien se dedicaba en especial al dibujo y elaboración de mapas y vistas, y no se conoce obra suya de otro género; desde I648 llevaba a cabo 
Por cortesía de las bibliotecas del Vaticano, Viena y Florencia, nos ha sido posible conocer, aunque sea sólo fotográficamente, algunas de las copias manuscritas hechas en el siglo XVII, cuando se pintaron las cuatro vistas de Juan Gómez de Trasmonte y Adrián Boot. ${ }^{14}$

Es justo hacer una digresión para exponer quiénes fueron los autores de las vistas y cuáles fueron las circunstancias que las originaron.

Juan Gómez de Trasmonte (?-c. 1647) fue un destacado arquitecto español, portugués según algunos investigadores, que trabajó la mayor parte de su vida en la construcción de la catedral de México donde desempeñó diversos puestos y responsabilidades hasta llegar al más importante de ellos: el de maestro mayor. También participó en la construcción de la catedral de Puebla e inició la construcción de la iglesia de San Lorenzo en la capital. Estuvo a cargo de reparaciones del Palacio Virreinal, la albarrada de San Lázaro y las acequias de la ciudad de México. Fue uno de los personajes que, hacia I624, emitieron su parecer acerca de las obras del desagüe que ejecutaba Enrico Martínez. ${ }^{15}$

Cuando en I607 se tomó la decisión de proceder con las obras del desagüe del valle de México, según el proyecto de Enrico Martínez, el virrey comisionó a Andrés de la Concha para que elaborara un plano de la ciudad mostrando todas las casas, iglesias, monasterios y hospitales, con el supuesto fin de facilitar el avalúo de todas las propiedades particulares para una distribución equitativa de los impuestos que se cobrarían para cubrir el costo de las obras. ${ }^{16}$ Es posible que el plano y la vista de México de Gómez de Trasmonte tuvieran la misma finalidad, ya que en 1627 y 1628 hubo inundaciones de proporciones desastrosas que obligaron a considerar de nuevo la posibilidad

trabajos encargados por Joan Blaeu, quien a veces los usaba, entre otros, como originales para sus grabados en cobre.

"Así que en el Atlas Blaeu-Van der Hem aparecen, del actual territorio mexicano, cuatro acuarelas que son de lo más interesantes, dos de la ciudad capital, una de Acapulco y una de Veracruz, los principales puertos del país sobre el Pacífico y el Atlántico. Todos ellos deben haber sido dibujados por Vingboons hacia I650 según originales de alrededor de 1630. El estilo de la representación corresponde ampliamente al del llamado Atlas secreto de la Compañia Holandesa de las Indias Orientales. (El atlas secreto constituye una parte del Atlas Blaeu-Van der Hem y abarca cuatro volúmenes. La Compañía Holandesa de las Indias Orientales fue fundada en 1602 y gozaba de un monopolio concedido por el gobierno para comerciar en los Océanos Índico y Pacífico)" (traducción del autor).

I4. Publicadas por primera vez en México en Mayer, op. cit.

I5. Fernández, op. cit.

I6. Wieder, op. cit., p. Iı. 
de trasladar la ciudad a terrenos más elevados que no corrieran el riesgo de ser cubiertos por el agua. En la copia de Florencia del plano de Juan Gómez de Trasmonte hay una leyenda en castellano que dice textualmente: "Tiene esta ciudad hasta Io ooo vezinos y de arrabales que son casas de Indios hasta nueve mil y estas la mayor parte están hoy anegadas, como todo se significa en esta Planta que esta sacada con puntualidad y cuydado Anno i628." En el plano del atlas del Vaticano este texto aparece en holandés y señala que los indios son pobres y que la mayoría de ellos se ahogó. ${ }^{17}$

La presencia en México de Adrián Boot se relacionó con los trabajos del desagüe del valle de México, cuyo objeto era evitar las frecuentes inundaciones que sufría la ciudad. En carta del 29 de mayo de I6ı2, el rey Felipe III de España le pidió a su embajador en Francia, don Yñigo de Cárdenas, que le encontrara un ingeniero capaz de inspeccionar los trabajos que se llevaban a cabo para el desagüe del valle de México y de dar una opinión sobre ellos. ${ }^{18} \mathrm{El}$ embajador recomendó al holandés Adrián Boot y desde París remitió, con carta del 29 de julio de I6I2, un plano denominado "Diseño de la ciudad de México y del virreinato de Nueva España desde el mar del Norte al del Sur, para instrucción del desagüe de la laguna de México"I9 (fig. 4). Es probable que Boot haya dibujado este mapa para reforzar su candidatura al puesto ofrecido. Boot obtuvo un nombramiento con cédula real del $\mathrm{I}^{\circ}$ de junio de I6I3, llegó a México en septiembre de I6I4 y su primera inspección de las obras del desagüe la realizó el I7 de noviembre de I6I4. ${ }^{20}$

Los trabajos los venía dirigiendo desde 1607 Enrico Martínez, quien según algunos autores era francés de nombre Henri Martin; ${ }^{21}$ otros afirman que

17. Ibidem, p. IIo. Fernández, op. cit., pp. 47-48, cita a Edmundo O'Gorman en Reflexiones sobre la distribución urbana colonial de la ciudad de México: "el I6 de noviembre de I628 el marqués de Cerralvo emitió una ordenanza [...] para organizar las rondas nocturnas que debían de realizar [...] tal vez con base en el plano de Gómez de Trasmonte y encargado previamente para ello". De haber sido así, este autor piensa que se habría grabado un plano con la ordenanza.

18. Fernando de Cepeda, Fernando Alonso Carrillo y Juan de Albares Serrano, Relación universal, legitima y verdadera del sitio en que está fundada la muy noble, insigne y muy leal ciudad de México, México, Salbago, I637.

19. Pedro Torres Lanzas, Archivo General de Indias. Catálogo de mapas y planos de México, Madrid, Ministerio de Cultura-Dirección General de Bellas Artes y Archivos, 1985, p. 48.

20. Jorge Gurría Lacroix, El desagüe de la ciudad de México durante la época novohispana, México, Universidad Nacional Autónoma de México-Instituto de Investigaciones Históricas, 1978, p. 97. En esta obra se cita frecuentemente la de Fernando de Cepeda referida en la nota I8.

2I. José Toribio Medina, La imprenta en México (I539-I82I), México, 1995 (reed. de la casa del autor en I912), tomo I, p. CX. 


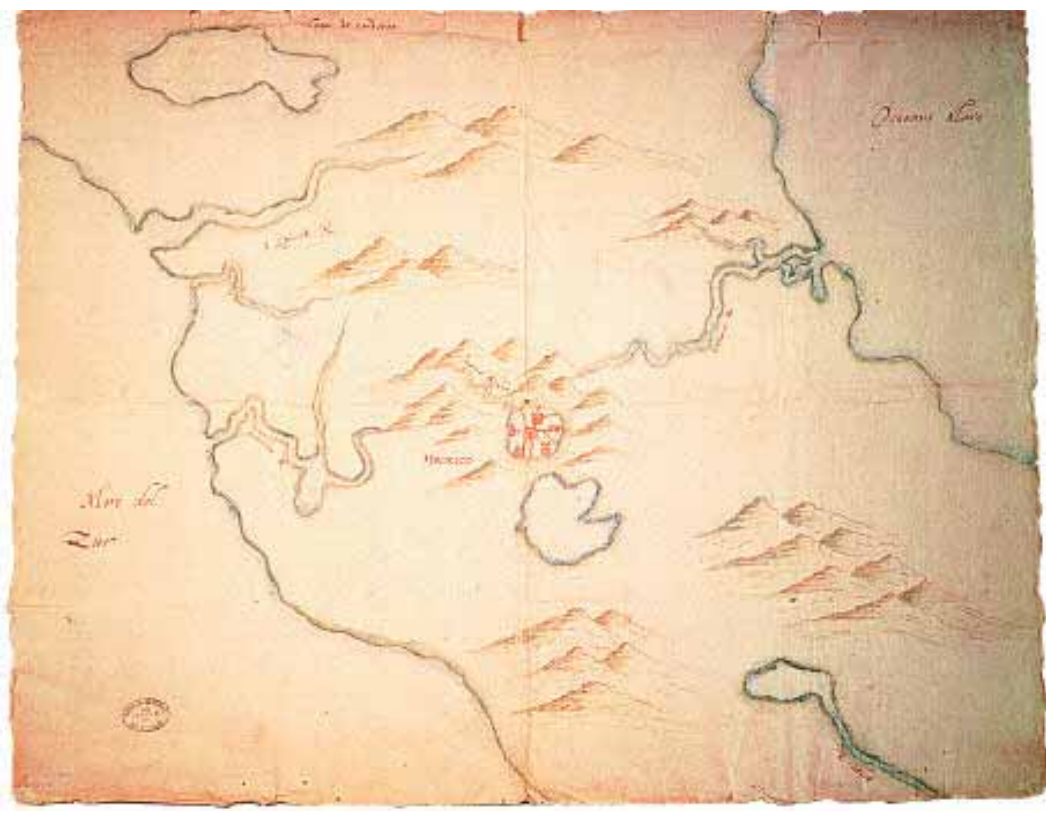

4. "Diseño de la ciudad de México y del virreinato de Nueva España desde el mar del Norte al del Sur, para instrucción del desagüe de la laguna de México", manuscrito de Adrián Boot, $33 \times 42 \mathrm{~cm}$. (C) Ministerio de Cultura. Archivo General de Indias, Torres Lanzas núm. 55 .

era alemán de nombre Heinrich Martin, con base en sus propias declaraciones ante el Tribunal de la Inquisición. ${ }^{22}$ Martínez tenía el cargo de cosmógrafo real, pero era también astrólogo, historiador e impresor; como además era políglota, sirvió al Santo Oficio de la Inquisición en calidad de traductor. ${ }^{23}$ Hoy se le recuerda como un gran ingeniero, ya que, desde 1607 hasta su muerte en I632, se dedicó en forma constante a las obras del desagüe, para las cuales proyectó un tajo en Nochistongo, en parte abierto y parcialmente cubierto, obra de ingenie-

22. Joaquín García Icazbalceta, Bibliografía mexicana del siglo XVI, A. Millares Carlo (ed.), México, Fondo de Cultura Económica, 1954, núm. 71, p. 38, y núm. 78, p. 55.

23. Ibidem, núm. 74, p. 54. 
ría asombrosa para su época. En honor a Enrico Martínez se edificó un monumento que hoy en día se encuentra frente al ángulo sur-poniente de la Catedral Metropolitana, y muestra las coordenadas geográficas del lugar, su altura sobre el nivel del mar, los niveles de algunos lagos del valle de México, un metro patrón y otros datos técnicos; este monumento ha sido usado como kilómetro cero de las carreteras que salen de la capital.

Adrián Boot no estuvo de acuerdo con el proyecto de Martínez por razones técnicas y por su elevado costo. Presentó uno propio en que propuso poner un cerco a la ciudad mediante diques y calzadas, expulsar las aguas sobrantes por medio de máquinas que se usaban en Holanda y construir canales para dar salida a las aguas, que también servirían para la navegación. ${ }^{24}$ Quizá para preparar ese proyecto, dibujó un mapa del valle de México que conocemos gracias a que lo publicó el viajero Giovanni Francesco GemelliCarreri, quien consiguió una copia exacta de su poseedor, a la sazón el matemático poblano Cristóbal de Guadalajara ${ }^{25}$ (fig. 5).

Este proyecto se consideró costoso y fue rechazado por el Consulado de la ciudad de México, autoridad responsable de esos trabajos en I6I5. En el mismo año, Boot fue enviado a Acapulco, donde permaneció hasta I6I7, para proyectar y construir mejoras al fuerte de San Diego, al que agregó cinco reductos, y durante los años I62I-I623 residió en Veracruz para mejorar los planos del fuerte de San Juan de Ulúa. Boot gozaba de un sueldo muy elevado para esa época: Ioo ducados al mes a partir de julio de $1613 ;{ }^{26}$ ello despertó envidia y causó intrigas de sus colegas, quienes lo acusaban de gastar grandes sumas de dinero, sin provecho, en las obras que tenía encomendadas en los fuertes de Acapulco y Veracruz. Eso se desprende de una carta que el rey de España le mandó al virrey el $\mathrm{I}^{\circ}$ de diciembre de $\mathrm{I} 636$, donde le recomienda escuchar a los colegas de Boot, tomando en cuenta que muchos de ellos podían ser sus enemigos y que él ya está "tan impedido y viejo, que para pocas cosas puede ser de provecho en cualquiera parte" ${ }^{27}$ Las intrigas evidentemente siguieron y surgió la sospecha de que po-

24. Gurría Lacroix, op. cit., p. 99.

25. Ola Apenes, Mapas antiguos del valle de México, México, Universidad Nacional Autónoma de México, 1947, p. 23, lámina 17. También se encuentra en Manuel Carrera Stampa, Planos de la ciudad de México (desde IS2I hasta nuestros días), Boletín de la Sociedad Mexicana de Geografia y Estadistica, núms. 2-3, t. LXVII, México, 1949, p. 347, lám. XII.

26. Gurría Lacroix, op. cit., p. 97.

27. Archivo General de la Nación, Reales Cédulas, vol. I, exp. 194, ff. 363-364v, I de diciembre de 1636 . 


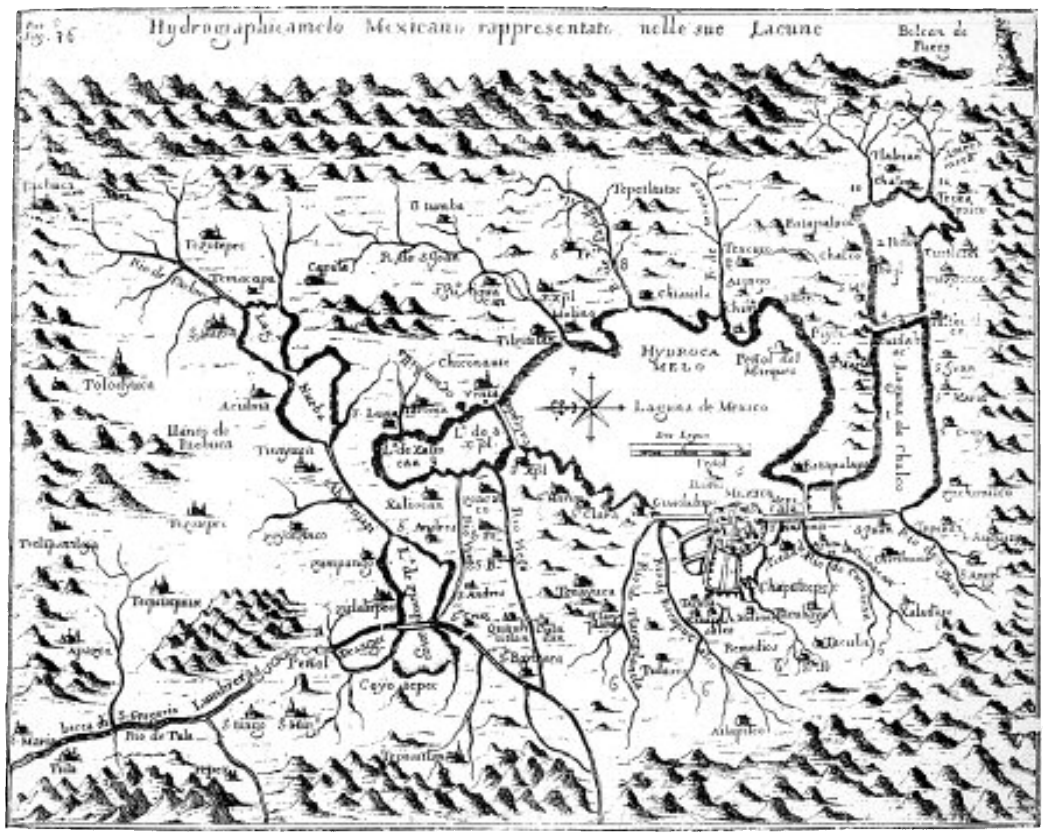

5. Hydrographicamelo mexicano representato nelle sue lacune, copiado de Adrián Boot grabado en cobre, 2I $\times 17 \mathrm{~cm}$, publicado en Gemelli Carreri, Nápoles, Giro del Mondo, 1700. Col. y foto del autor.

día ser espía. ${ }^{28}$ Así, el I7 de septiembre de I637 la Inquisición se presenta en casa de Boot, levanta un detallado inventario de sus bienes y lo encarcela en un lugar secreto que resultó ser el Colegio de la Compañía de Jesús. Al poco tiempo se subastaron algunos de sus bienes, seguramente para solventar gastos del juicio, pero el I9 de abril de 1638 es liberado y se le restituyen todas sus propiedades. ${ }^{29}$ No se ha encontrado información posterior sobre Adrián Boot.

28. Archivo General de la Nación, Inquisición, vol. 489, exp. 6, ff. 75 y 76, 3 de septiembre de 1637 .

29. Archivo General de la Nación, Inquisición, vol. 383, exp. Io, ff. 75-76, 363-364v, inventario de los bienes de Adrián Boot. Por ese inventario sabemos que era un hombre muy culto, pues poseía un número considerable de libros en varios idiomas y muchos mapas de diversas regiones del mundo, además de los instrumentos propios de su profesión. 
El 4 de agosto de I895 se publicó en La Voz de la Verdad (número 3I, tomo III) una extensa carta firmada por Borja y fechada el 30 de abril de 1895 , acompañada de una litografía que Troncoso dirigió a su amigo, coterráneo veracruzano y compañero de escuela, el señor don Gonzalo A. Esteva, a la sazón ministro de México en Italia. La carta se vuelve a publicar en 1922 en el número 3 de la recopilación de documentos de Troncoso preparada por Galindo y Villa. ${ }^{30}$ El autor dice ahí: "De mis materiales, no es la parte menos interesante la cartográfica. Algo le diría de los planos [...] le quiero hablar mejor de otro que, por pertenecer a la Veracruz Nueva, estudié con cuidado en Madrid, y del cual conservo entre mis papeles una descripción a vuelta de pluma. El original (del que obtuve copia para el Museo de México) está en Viena”. ${ }^{\mathrm{I}}$ Más adelante señala: "Cromolitografía de 62 centímetros de anchura por 55 de alto que reproduce una vista original de la Nueva Veracruz editada por el señor Troncoso en la casa florentina de A. Ruffoni. Ya se dijo bastante en las páginas 387 y siguientes". ${ }^{32}$ Luego describe la Vista de la ciudad de México en 1628 por Juan Gómez de Trasmonte, ${ }^{33}$ con créditos similares, y la Vista del Puerto de Acapulco, "la tercera de las reproducciones [...] con su respectiva explicación que termina con la firma de A. Boot. ${ }^{34}$

Silvio Zavala, con gran tesón, hizo una lista del enorme conjunto de documentos que Troncoso reunió o copió durante sus 24 años de estancia en Europa. La publicó incluyendo en su título el nombre del ilustre antiguo director del $\mathrm{Mu}-$ seo Nacional (véase nota I). ${ }^{35}$ En una de sus comunicaciones a la Secretaría de Instrucción Pública, aparece un párrafo importante para el tema que nos ocupa:

Los dos planos en negro contenidos en la pieza 5 forman parte de una colección de tres plantas ${ }^{36}$ de ciudades mexicanas que se conserva en la Biblioteca Imperial

30. Galindo y Villa, op. cit., pp. 369-387.

31. Ibidem, p. 370. 3. Descripción de la ciudad de Tablas.

32. Ibidem, p. 522. 39. Vista de la Nueva Veracruz.

33. Ibidem, p. 522. 40. Vista de la ciudad de México en I628.

34. Ibidem, p. 540. 4I. Vista del puerto de Acapulco.

35. Zavala, op. cit., p. 23: "El señor Del Paso y Troncoso desde Madrid, a 2I de abril de I906, avisa que remite diversas piezas publicadas por él. Añade informes importantes sobre sus trabajos y detalla el contenido de las series de Papeles de la Nueva España”, Archivo General de la Nación, exp. 318, leg. 6, núm. I, ff. 44-45v.

36. Trasmonte repetidamente usa la palabra planta para describir lo que nosotros hoy nombramos vista panorámica. 
de Viena. Se hace la tirada en Florencia, con todo esmero, no sólo de los dos planos de México y Veracruz, remitidos esta vez, sino también del de Acapulco. Se han ido estampando desde hace tiempo, por estar en colores, pero no mando los tres ahora porque no han llegado todavía los ejemplares pedidos: resulta espléndido su efecto en colores y de ello juzgará Ud. cuando los vea. El plano de México se levantó un año antes de la grande inundación de I629 que duró varios años y cambió radicalmente la planta de la ciudad en los suburbios; así es que lo reputo como inapreciable documento para la historia de nuestra capital; fue levantado en I628 por Juan Gómez de Trasmonte cuyo apellido paréceme portugués. La planta de Acapulco, de la cual pronto remitiré a Ud. un ejemplar, fue levantada por el célebre ingeniero flamenco Adrián Boot, enviado a Nueva España en el reinado de Felipe III con motivo del desagüe de México. El plano de Veracruz, comparado con el de Acapulco, resulta muy semejante, por los colores empleados y por el carácter de los dibujos: me ha hecho la impresión, siempre, de ser obra también de Adrián Boot, y esto mismo han sentido cuantos inteligentes los han examinado. Serán estos tres planos, que se han reproducido sin reducción, el núcleo de una colección geográfica que tendrá grande interés para el estudio de nuestra historia como colonia, si Ud. aprueba las ideas que van expuestas en mi oficio número $7 \cdot{ }^{37}$

Más recientemente, Manuel Carrera Stampa levantó un nuevo inventario de los documentos reunidos por Troncoso, el cual confirma y amplía el registro de Zavala. ${ }^{38}$

\section{Conclusiones}

Los escritos de Francisco del Paso y Troncoso, cuyos documentos fueron recopilados por Jesús Galindo y Villa, Silvio Zavala y Manuel Carrera Stampa, dejan perfectamente claro que el autor obtuvo copias de las vistas de Vingboons del Atlas Blaeu-Van der Hem, que se conservan en la Österreichische Nationalbibliothek de Viena, para producir las cromolitografías con los panoramas de México, Acapulco y Veracruz en la casa florentina de A. Ruffoni.

37. Galindo y Villa, op. cit., pp. 26-27.

38. Manuel Carrera Stampa, Misiones mexicanas en archivos europeos, México, Instituto Panamericano de Geografía e Historia, I949. 
Sin embargo, siguen persistiendo varias situaciones misteriosas. ¿Cómo es que se encontraban en Midelburgo las cuatro pinturas originales de Juan Gómez de Trasmonte y Adrián Boot, que Vingboons copió para el atlas localizado en Viena y que a su vez sirvieron como originales para las cromolitografías hechas en Florencia y puestas a la venta en el Museo Nacional de México?

Los originales de las vistas pintadas por Boot de Acapulco (donde sabemos que estuvo entre I6I5 y I6I7) y Veracruz (donde sabemos que estuvo entre I62I y I623), y la de la ciudad de México pintada por Trasmonte (con fecha I628, según la descripción de Troncoso) ya se encontraban en el palacio del ayuntamiento de la ciudad costera de Midelburgo, Holanda, en I632, según su inventario de ese año: ¿cómo llegaron ahí? Tenemos datos de que Boot estuvo en México entre I6I3 y I638 y es poco probable que haya regresado a su terruño, Holanda, entre 1628 y I632, llevando consigo las pinturas, pues se le describía como persona mayor y, de haber hecho el viaje, lo más probable es que se hubiera quedado en su tierra natal. Desconocemos los lazos familiares de Boot que hubieran podido retenerlo o hacerlo regresar a México. Una posible explicación es que algún viajero holandés haya adquirido las pinturas de Trasmonte y Boot, y las haya llevado a Holanda en esos años. Otra posible respuesta es que Boot las haya enviado a su ciudad natal, lo cual no se puede verificar, ya que se desconocen el lugar y la fecha de su nacimiento, y los archivos de aquella época desaparecieron, ${ }^{39}$ al igual que las pinturas, víctimas de la segunda guerra mundial.

Un hecho que no se entiende es que Troncoso, quien manifestó su gran interés por la cartografía, solamente haya copiado la vista de la ciudad de México y no el plano de la misma que levantó Trasmonte, el cual revestiría gran importancia para nosotros, pues el número de levantamientos que se hicieron en la capital de la Nueva España en la primera mitad del siglo XVII es muy reducido.

Persiste el enigma de los comentarios de Gómez de Orozco sobre una carta de Troncoso donde éste señala que el original del plano de Trasmonte estuvo en una colección privada en Bélgica, y tal vez en la misma colección los planos de Veracruz y Acapulco, y expresa su gran satisfacción al saber que un amigo suyo tenía en ese tiempo los originales en México. Sólo se puede especular sobre los fundamentos de estas aseveraciones. Tal vez se trate de los dibujos acuarelados que se debieron hacer en la biblioteca de Viena para servir de originales con el

39. Correspondencia electrónica del autor con el doctor Peter van der Krogt, Universidad de Delft, Holanda, agosto de 2003. 


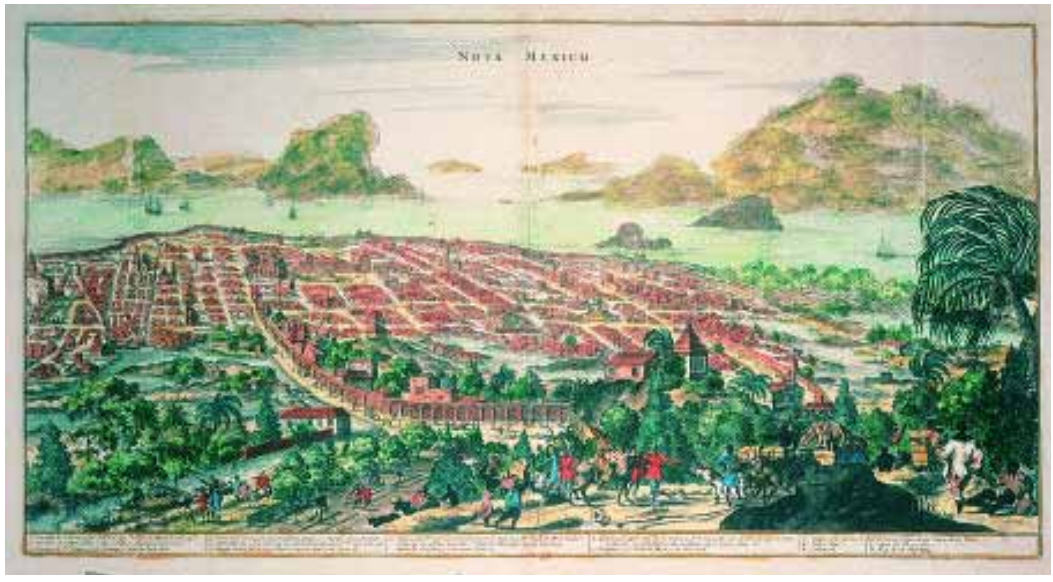

6. Nova Mexico, John Ogilby, en el libro America..., Londres, Thos. Johnson, I67I, grabado en cobre acuarelado, $28.5 \times 54 \mathrm{~cm}$. Col. del autor. Foto: Adrián Bodek.

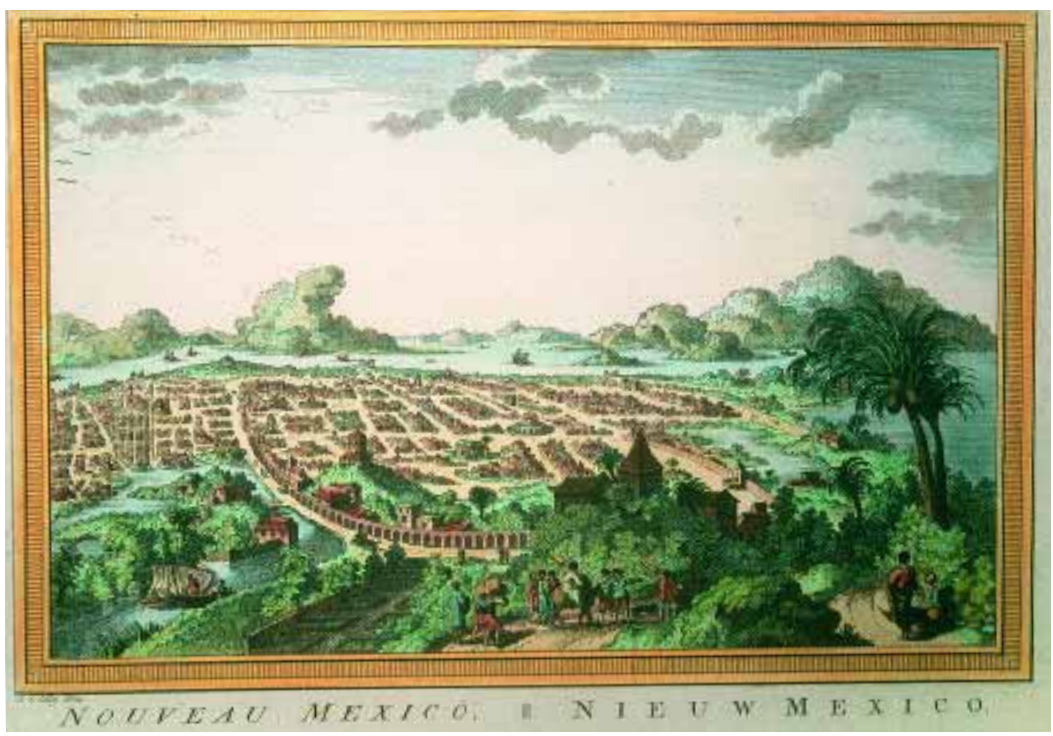

7. Nouveau Mexico-Nieuw Mexico, J. Schley, I747, La Haya, en el libro Histoire générale des voïages..., grabado en cobre acuarelado, $18 \times 28 \mathrm{~cm}$. Col. del autor. Foto: Adrián Bodek. 
fin de llevarlos a las piedras litográficas en Florencia. De estos “originales" pudo haber dispuesto el impresor o el artista que los hizo, y así llegaron a Bélgica. Sin embargo, sorprende que, después de tantos años, no se supiera nada de esos dibujos y que no se hubieran exhibido en alguna de las muchas exposiciones de ilustraciones antiguas de nuestro país, donde habrían causado sensación entre los aficionados a la historia gráfica de México. También sorprende que Gómez de Orozco no haya estado al tanto de los escritos de Troncoso, recopilados por Galindo y Villa y publicados en I922, en los cuales el autor informa que los originales de las vistas estaban en Viena; posiblemente su texto para el libro Planos de la ciudad de México se tuvo que hacer con demasiada premura.

\section{Epílogo}

La vista de la ciudad de México de Juan Gómez de Trasmonte fue copiada para ilustrar varios libros, quizás por vez primera en America ... ${ }^{40}$ en I670 (fig. 6). También se le encuentra en La galerie agréable du monde,$^{4 \mathrm{I}}$ publicada alrededor de I729, y en las diversas ediciones de Histoire générale des voïages... ${ }^{42}$ (fig. 7), publicadas originalmente entre 1754 y 1789 , y traducidas a varios idiomas. Resulta curioso que hacia 1865 , durante el imperio de Maximiliano, tal vez por no encontrar alguna ilustración más reciente, un periódico holandés publicara nuevamente la vista de Trasmonte, que ya tenía más de doscientos años de antigüedad, para ilustrar nuestra ciudad capital, haciéndole algunos cambios (fig. 8).

40. John Ogilby, America: Being an Accurate Description of the New World, Londres, Thos. Johnson, I670. La vista Nova Mexico aparece como un grabado en cobre desplegable de $28.5 \times 54 \mathrm{~cm}$ entre las páginas 262 y 263 . La misma obra fue publicada el mismo año en holandés, con pocas diferencias, por Arnoldus Montanus bajo el título De Nyeuwe en Onbekende Weereld: of Beschryving van America en 't Zuid-Land..., Amsterdam, Jacob von Meurs, I673. Esta casa editora publicó posteriormente la traducción al alemán del autor, doctor O. D[apper] en I673, con el título Die Unbekannte Neue Welt oder Beschreibung des Welt-teils Amerika, und des Sud-Landes... Información tomada de Joseph Sabin, A Dictionary of Books Relating to America from its Discovery to the Present Time, Nueva York, Mini-Print, 1967.

4I. Pieter van der Aa, La galerie agréable du monde, Leiden [1729]. La ilustración La grande Ville de Mexico, dans l'Amérique Septentrionale. Nova Mexico, aparece en la página is como un grabado en cobre de $28.5 \times 54 \mathrm{~cm}$.

42. [Antoine François, Prevost D’Exiles], Histoire générale des vö̈ages ou nouvelle collection de toutes les relations de voïages par mer et par terre..., París, Didot, I754. La ilustración aparece en el vol. XII. 


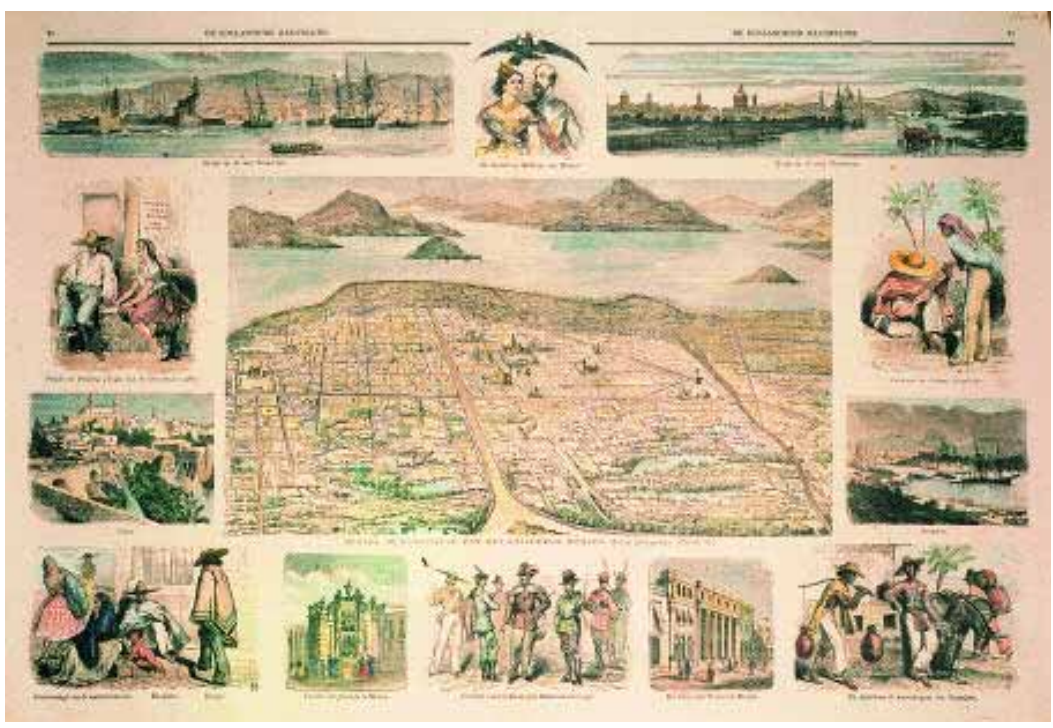

8. Anónimo, México, de Hoofstadt Van Het Keiserrijk México, Amsterdam, 1865, del periódico De Hollandsche Illustrierte, xilografía coloreada, $35 \times 52 \mathrm{~cm}$. Col. del autor. Foto: Adrián Bodek.

El doctor Wieder opina que el plano de la ciudad de México de Nicolás de Fer (fig. 9) se basa en el de Juan Gómez de Trasmonte, "ya que existe un parecido evidente, aunque la orientación es distinta, y no se sabe que De Fer haya contado con otra fuente". ${ }^{43}$ Este autor también le encuentra un fuerte parecido con alguno de los planos basados en el que se le ha atribuido a Hernán Cortés, con la misma orientación, y considera que De Fer probablemente los combinó, en un intento de actualizar el del conquistador con información tomada del plano de Trasmonte.

La vista de Acapulco de Adrián Boot fue copiada y grabada en cobre, en varios atlas del siglo XVIII, entre otros por el cartógrafo François Valentyn ${ }^{44}$ (fig. IO).

43. Wieder, op. cit., p. I37.

44. François Valentyn, Haven van Aquapulco in t'Coninkryk van Nova Spagnien in de Zuyd Zee, Amsterdam [1724-1726]. Aparece en Oud en Nieuw Oost Indien, núm. 5. 


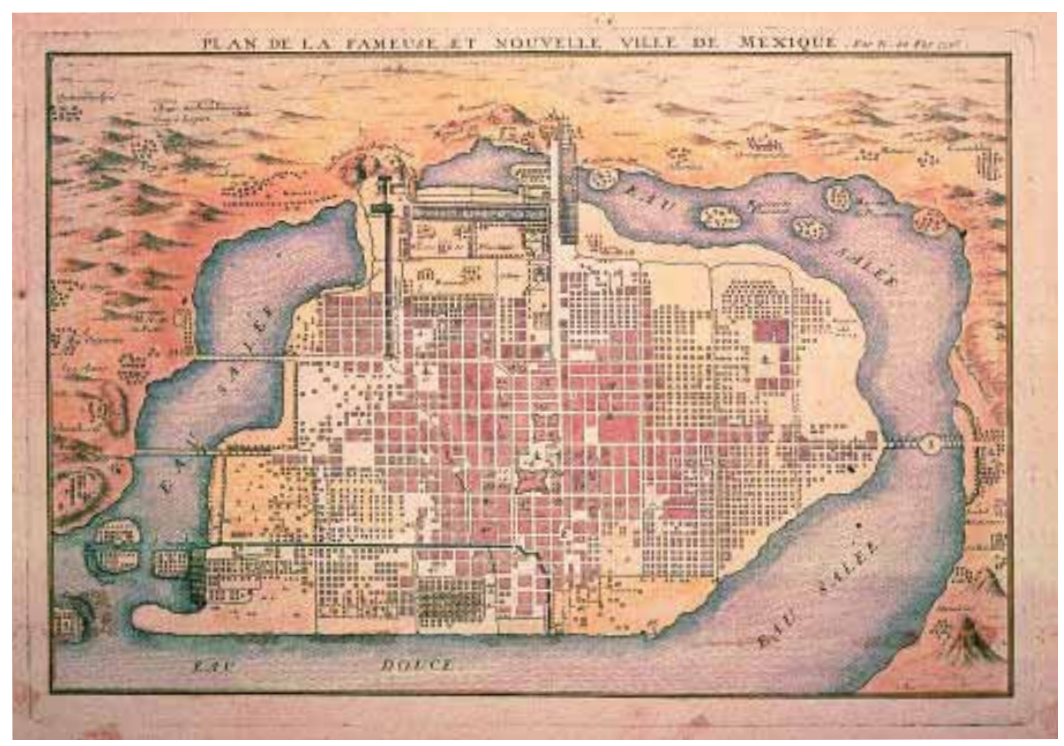

9. Nicolás de Fer, Plan de la fameuse et nouvelle ville de Mexique, París, 1715, grabado en cobre, $22.2 \times 33 \mathrm{~cm}$. Col. del autor. Foto: Adrián Bodek.

\section{Posdata}

A finales de noviembre de 2004 recibí un correo electrónico que dice: "Encontré en internet su comunicación con MapHist, ${ }^{45}$ con referencia al ingeniero Adrián Boot. En efecto las pinturas (de hecho acuarelas) de Boot de Acapulco y de Veracruz se encuentran juntas con las dos de Trasmonte de la ciudad de México. Mi padre adquirió las cuatro, en una librería de viejo en Amberes, poco después de la segunda guerra mundial."

Pasados unos días me reuní con el dueño de las acuarelas. Tuvimos varias reuniones para estudiarlas cuidadosamente. Adicionalmente comparamos las

45. MapHist es un foro en internet donde puede uno solicitar información, respuestas y comentarios sobre temas cartográficos, obteniendo a menudo información de alguno de los aproximadamente seiscientos socios. Había yo enviado un mensaje en abril de 2003 , solicitando información sobre la fecha de nacimiento y otros posibles datos sobre Adrián Boot. 


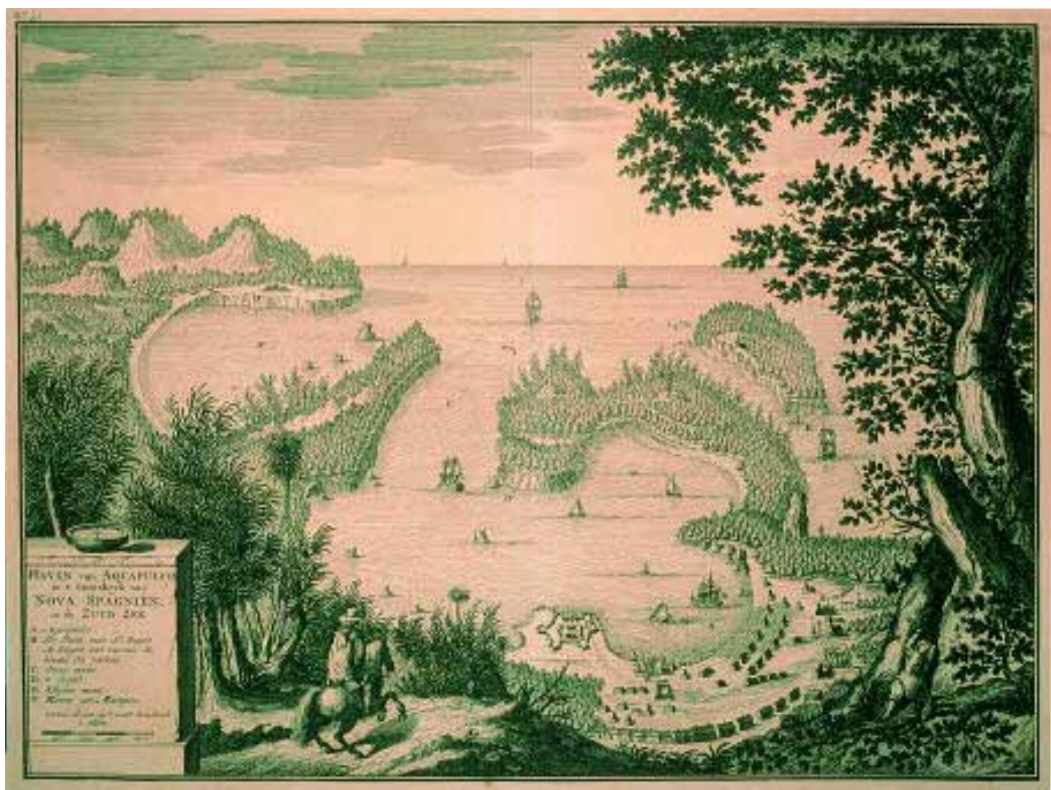

Io. François Valentyn, Haven von Acapulco, Amsterdam, 1724, grabado en cobre, $27 \times 36 \mathrm{~cm}$. Aparece en Oud en Nieuw Oost Indien, p. 5. Col. del autor. Foto: Adrián Bodek.

acuarelas con las vistas que se encuentran en las bibliotecas de Florencia, Viena y el Vaticano; observamos que algunas de ellas tienen parecido con las vistas de una biblioteca y otras con la de otra. En algunas de las vistas se distingue una cuadrícula que el artista pudo haber hecho para copiar de un atlas o para pasar la vista a la piedra litográfica. Comparamos cada una de las acuarelas con la cromolitografía respectiva de Ruffoni, las cuales también acusan cuadrículas, pero las cuadrículas no corresponden y hay grandes diferencias en el colorido y en otros detalles; solamente una se parece a la cromolitografía respectiva. Además observamos que hay detalles dentro de las vistas que también difieren, sobre todo en lo que se refiere a zonas inundadas o no inundadas en la ciudad de México. De todo esto se concluye que estas acuarelas no fueron los originales de las cromolitografías.

Aún subsiste la duda de si las acuarelas son de la mano de Vingboons, aunque ninguna lleva su firma y no todas las acuarelas de los multicitados 
atlas están firmadas. Se hizo un croquis de la filigrana (marca de agua) del papel de una de las acuarelas y un especialista en Venezuela dice que la marca de agua corresponde a un papel fabricado en Berna, Suiza, y que fue utilizado en los años I633 y i635-1636 en los grabados de Rembrandt. Esto demuestra que las acuarelas son de la época de Vingboons.

En Monumenta cartographica... (véase nota 7), el Dr. Wieder menciona un cuarto atlas con las cuatro acuarelas de ciudades mexicanas por Vingboons, diciendo que este atlas cayó en las manos de la empresa de libros antiguos de Fredrik Muller, quien dispersó el atlas y vendió las hojas sueltas en subasta pública en 1885. Así llegaron a estar sus mapas y vistas en diversos rincones del mundo, pero el Dr. Wieder pudo localizar muchas de ellas. En I932 encontró sesenta y tres de un total de setenta y seis mencionadas en el catálogo, treinta y cuatro mapas se encuentran en Recife, Brasil, cinco en la Bibliothèque Nationale de París, trece en la Library of Congress en Washington y once en Rotterdam. En 1948 el historiador especializado en cartografía, Leo Bagrow, publicó un opúsculo ${ }^{46}$ ilustrando otros cuatro mapas de Vingboons que se encontraban en Suecia. Una de las hojas localizadas en Recife lleva el número II4, lo cual sugiere que el atlas tuvo un mínimo de II4 hojas; se desconoce el paradero de las demás páginas.

La conclusión a la que podemos llegar es que las cuatro acuarelas, que afortunadamente se encuentran en México, son de mediados del siglo XVI, muy probablemente del atlas que dispersó Muller en 1885 y, si no de la mano de Vingboons, entonces de alguno de los artistas que trabajaban bajo su directa supervisión. \$ 